\title{
Dynamic Soil Stiffness Between WAK, SASW and SCPT Tests
}

\author{
Norazzlina M. Sa'don, Michael John Pender \\ and Abdul Razak Abdul Karim
}

\begin{abstract}
This paper describes an experimental investigation for determining the dynamic soil stiffness by applying the principles of WAK (wave-activated stiffness $[\mathrm{K}])$ test analysis, spectral analysis of surface waves (SASW) method and seismic cone penetration test (SCPT). The WAK and SASW tests were performed by applying an impact load on a circular steel plate of $50 \mathrm{~cm}$ diameter in vertical direction. A sledgehammer equipped with a dynamic force transducer was used to produce the impact load. The force time signal from the dynamic loading (input) and acceleration time signals from vertical accelerometers (output) were recorded during the tests. The dynamic stiffness of soil was obtained by considering the soil to be vibrating as a single degree of freedom (SDOF) system. The SCPT was performed by measuring the travel times of body waves propagating between a seismic shear wave source at the ground surface activated at each level and an array of geophones. The dynamic soil stiffness obtained from WAK and SASW tests compared very well with the SCPT test.
\end{abstract}

Keywords WAK $\cdot$ SASW $\cdot$ Dynamic $\cdot$ Soil stiffness $\cdot$ Shear modulus

\section{Introduction}

In situ geophysical tests have become very important tools for the evaluation of dynamic soil properties and are specially well-suited for hard-to-sample soils. In particular, seismic tests supply good quality data regarding soil behaviour at very

N. M. Sa'don $(\bowtie) \cdot$ A. R. A. Karim

Department of Civil Engineering, Universiti Malaysia Sarawak (UNIMAS),

Kota Samarahan, Sarawak, Malaysia

e-mail: msazzlin@feng.unimas.my

M. J. Pender

Department of Civil and Environmental Engineering, The University of Auckland,

Auckland, New Zealand

R. Hassan et al. (eds.), InCIEC 2013, DOI: 10.1007/978-981-4585-02-6_40,

(C) Springer Science+Business Media Singapore 2014 